\title{
Two-Cored Energy Management System for Industrial Microgrid
}

\author{
Saqib Ali ${ }^{1}$, Tahir Nadeem Malik $^{2}$ \\ RECEIVED ON 30.08.2019, ACCEPTED ON 03.03.2020
}

\begin{abstract}
Energy systems have to deal with energy cost and environmental concerns such as greenhouse gas emission. Industrial buildings considered as Microgrid $(\mu \mathrm{G})$ with heavy load worsen these issues even more. Further, cyber-attacks on the data communication channel between utility and customer is also a potential threat and may alter the data as well as the confidentiality of it, resulting in an inaccurate result. To address these problems, this paper proposes two-cored Building Energy Management System (BEMS) for Industrial Microgrid $(\mathrm{I} \mu \mathrm{G})$ with first cored termed as the energy layer concentrating on energy cost and emission reduction, while second cored termed as security layer provides the un-authorized intrusion detection and prevention system (IDS/IPS) for cyber secure communication of data. The $\mu \mathrm{G}$ under consideration contains national grid, Natural Gas (NG), solar Photovoltaic (PV) as input carriers; electrical energy at output ports; electric vehicle (EV) fleet; battery bank; solar PV panel as non-dispatchable Distributed Energy Resources (DERs) and Internal Combustion Engine (ICE), Fuel Cell (FC) and Micro Turbine (MT) as dispatchable DERs. Energy layer optimization problem has been solved in MATLAB using flower pollination algorithm for $\mu \mathrm{G}$ energy consumption cost and emission reduction. To develop and analyze the security layer, Linux operating system based Smooth-sec software has been used. Devised security layer continuously monitors the network traffic between customers and BEMS as well as BEMS and utility server. During monitoring it distinguish the licensed user or malicious attacker to detect and prevent possible internal and/or external intrusions in the communication channel. Results show that EMS reduces energy cost and emission in addition to cyber security from internal threats. Proposed two-cored control may be manufactured for utilities to realize its benefits for industrial customers in a smart energy distribution system.
\end{abstract}

Keywords: Demand Response, Energy Management System, Flower Pollination Algorithm, Linux Operating System, Industrial Microgrid.

\section{INTRODUCTION}

$\mathrm{R}$ ising fuel cost, imbalance in ecological system and overloading of energy resources Demand Response (DR) strategies may effectively be used to solve these problems. The DERs reside in a $\mu \mathrm{G}$ as onsite generation to serve the connected load and sell excess power to national grid using net metering.
Such active contribution of a building reduces energy consumption cost, emission and network load. Demand response schemes influence the energy consumption pattern of customer to shift the load from peak to off-peak hours for energy consumption cost and overload reduction. Microgrid contains these two solutions, therefore, may prove effective to resolve energy distribution system challenges. Among various customer classes, industrial buildings are large in size and load, consequently, may affect the energy

\footnotetext{
${ }^{1}$ Department of Electrical Engineering, NFC Institute of Engineering and Technology, Multan, Pakistan. Email: saqib.ali@nfciet.edu.pk (Corresponding author).

${ }^{2}$ Department of Electrical Engineering, HITEC University, Taxila, Pakistan. Email: tahir.nadeem @ hitecuni.edu.pk This is an open access article published by Mehran University of Engineering and Technology, Jamshoro under CC BY 4.0 International License.
} 
consumption cost, emission and system overloading more meaningfully. Therefore, a mechanism to optimally control energy resources, load and storages for this type of customers' needs to be devised. The literature survey related to energy management system cost and emission in a $\mu \mathrm{G}$ is presented in detail.

Ranjith et al. [1] compared single core and multicore processor for the Home Energy Management System (HEMS) in term of effective cost and performance by utilizing multicarrier energy resources. The system contains solar PV, battery bank, utility supply and load. The allocated tasks for the first core are communication with room controller and continuous load assessment. The purpose of the second core is battery state of charge estimation, management of energy consumption and encryption of communication data. Results show that execution time of processor decreases from $1.88 \mathrm{~ms}$ to $1.42 \mathrm{~ms}$ and speed increases from $1 \mathrm{~ms}$ to $1.32 \mathrm{~ms}$ while using single and dual core processors respectively.

Lokeshgupta et al. [2] proposed a multi-objective Energy Management System (EMS) for residential consumers' to minimize their energy cost and load fluctuations. The building contains utility grid, Battery Energy Storage System (BESS) and shift-able and critical appliances. The problem is solved in MATLAB using mixed integer linear programming for four buildings. The results show that the customers can recover their BESS investment within three years with total saving of about 565.75 \$/year.

Senemar et al. [3] proposed optimal sizing strategy of combined heat and power unit, gas boiler, PV panel, and storages for residential energy hub under minimization of energy cost as objective function. The energy cost contains the capital investment and operation and maintenance charges. Devised framework has been validated under deterministic and random solar irradiance. Scenario generation and reduction is carried out using Monte-Carlo simulation. Proposed model is solved in General Algebraic Modeling System (GAMS) using CONOPT solver. Cost increases from $48083 \$$ to $48115 \$$ with and without solar irradiance uncertainty respectively.

Rosales-Asensio et al. [4] considered an office building located in the city of Palmdale, California, as large microgrid containing PV system and electrochemical energy storage systems, life cycle cost of energy, and electrical network. The model is formulated as mixed integers linear programming problem. The simulations show that proposed framework results in energy cost saving of $112,410 \$$ over the 20-year life cycle.

Mbungu et al. [5] proposed a model predictive based energy management and control framework for a commercial building in Tshwane, South Africa. Building contains photovoltaic system, utility grid and battery storage. The proposed technique is solved in MATLAB. The result manifests that cost of energy import decreases by $46 \%$.

Liang et al. [6] proposed a DR strategy for a commercial building to optimally schedule heating, ventilation, air conditioning systems, electric water heaters and plug-in electric vehicles. Building consists of power grid, battery, EV, solar PV penal, electric water heater and heating ventilation and air conditioning system. The objective is to minimize total energy cost and maximize customers comfort level. Monte Carlo method is used to generate scenarios of solar irradiance. The results demonstrate that household comfort level increases from $40 \%$ to $100 \%$ by sacrificing $20 \%$ of energy cost.

Blake et al. [7] proposed an $\mathrm{I} \mu \mathrm{G}$ equipped with wind turbine, Combined Cooling, Heating and Power (CCHP) unit in addition to battery for a manufacturing facility in Ireland. Load and wind speed have been forecasted using neural networks. Linear optimization problem aims at to solve cost and emission of $\mu \mathrm{G}$ using MATLAB. Results show that CCHP and wind turbine reduce cost by $69 \%$, while the emission reduces by $88 \%$.

Li et al. [8] presented an optimal energy management strategy for economic operation of wind, PV, diesel generator and vanadium redox flow as well as lithiumion batteries in an $\mathrm{I} \mu \mathrm{G}$ situated in Beijing, China. Performance objectives include fuel cost, maintenance charges and power purchasing cost reduction along with revenue maximization. Simulation is performed in regrouping particle swarm optimization algorithm. 
Results have been compared with the existing algorithms available in literature. Simulations show that the proposed energy storage strategy reduces the desired cost along with rise in revenue.

Golmohamadi et al. [9] proposed a multi-agent optimization structure to quantify the flexible load in cement and aluminum smelting industrial buildings for energy cost reduction. The proposed approach has been tested on the Danish sector of the Nordic Electricity Market. The stochastic programming approach is coded in GAMS while the results are imported in MATLAB. The simulations show that energy cost decreases by adding renewable energy by $18 \%$ and $34 \%$ for cement and smelting industries respectively.

Naderi et al. [10] proposed a $\mu \mathrm{G}$ in Shad-Abad industrial estate, Tehran, Iran. Microgrid contains wind turbine, battery, PV penal, FC, diesel generator and electrolyzer for production of Hydrogen. The objectives are stability enhancement of the network as well as energy cost reduction and emission minimization. Proposed problem has been solved in HOMER Pro. The results show that the net cost and $\mathrm{CO}_{2}$ emission have been minimized by $\$ 1.87 \mathrm{M}$ and $90000 \mathrm{~kg} /$ year.

Mehta [11] proposed a group of commercial and industrial microgrids while considering various options such as diesel generator, BESS and solar PV generation for a glass factory in India. Proposed problem is solved in HOMER Pro. Results demonstrate that fuel cost and energy consumption cost reduce by $45 \%$ and $19 \%$ respectively.

Choobineh et al. [12] considered a cluster of $\mu \mathrm{Gs}$ in an industrial park. Energy price and plant production have been taken as uncertain variables using robust optimization technique. Each $\mu \mathrm{G}$ consists of diesel generators. Proposed problem has been solved using goal programming technique. Devised central controller reduces energy cost of individual industrial buildings using game-theoretic approach.

Khripko et al. [13] presented a polymer processing factory equipped with CCHP unit, solar PV, gas boiler, electric boiler, absorption chiller, heat exchanger, thermal oil system, printing machine, dryer, blow film extruder, air compressor, compression chiller and water storage. The proposed linear optimization framework has been solved in GAMS. Results show that energy demand reduces by $23.19 \%$ after inclusion of renewable energy resources.

Helin et al. [14] offered an EMS for mechanical pulp production process in the Nordic power market. The microgrid contains natural gas-based CCHP, district heating system and electricity as inputs and electricity and heat as output carriers. Devised methodology generates an optimized operational plan for pulp production. Framework has been solved in CPLEX solver. Results demonstrate that industrial Demand Side Management (DSM) has sufficient flexibility to ensure network stability and energy consumption cost minimization.

Tan et al. [15] proposed time series simulations for a period of ten years in HOMER Pro software to evaluate the long-term impact of multiple energy sources in an $\mathrm{I} \mu \mathrm{G}$. The proposed model consists of diesel generator, wind turbine and national grid to analyze economic benefits and carbon emission reduction. The proposed scheme with emission proves more economical having total energy cost of $6.5744 \times$ $10^{7} \$$, however, cost rises to $6.6827 \times 10^{7} \$$ without inclusion of emission. Results show that the total carbon emission is $10,946,355 \mathrm{~kg} / \mathrm{yr}$.

Abdulaal et al. [16] developed a multi-objective GAbased optimization solver from quadratic, stochastic, and evolutionary programming, to solve a DR-based two-stage energy management system for $I \mu G$ in Florida. In stage-1, the optimizer shifts the shift-able load, whereas, the stage- 2 control continuously manages the controllable loads. Simulation showed a reduction in utility costs from $2 \%$ to $6 \%$ for Pareto optimal sets.

Apart from research work on energy layer of BEMS a cyber security strategy also needs to be developed to detect and prevent malicious attacks. Such attacks may modify weather as well as tariff data and customer preferences causing BEMS to malfunction, resulting in erroneous energy cost and emission. The cyberattack on the data communication channel between the 
$\mathrm{I} \mu \mathrm{G}$ and the utility may alter the data as well as its confidentiality.

The literature survey related to cyber security is described in detail as:

Anuebunwa et al. [17] analyzed the impact of cyberattack on load scheduling applications in a residential building. Attacker interferes with the critical data such as dynamic pricing information and load profile etc. Objective function includes impact on occupant comfort, cost and load variations. Proposed framework has been solved in Genetic Algorithm (GA). Devised scheme detects the false data injection to warn the system administrator to take remedial measures.

Yilmaz et al. [18] proposed rule based testbed in Smooth-sec software to detect the active attacks on programmable logic controllers in an industrial control system by using the mirroring technique. Under this strategy system compares the attack log file with the signature file residing in snort library to discriminate between the normal and obnoxious data to generate a warning massage for system administrator.

Otuoze et al. [19] highlighted various security challenges and threats i.e. physical attacks, cyberattacks or natural disasters which could lead to infrastructural failure, blackouts, energy theft, customer privacy breach and endangered safety of operating personnel etc. Authors also proposed a framework that can identify the security level, source and cause of threat and the impact of attack. The devised technique identifies and clears the threat.

Literature survey shows that EMS modules for residential and commercial buildings have already been devised to attain objectives such as energy cost and emission reduction. Likewise, EMS frameworks for small and medium scale industrial $\mu$ Gs have already been proposed. However, EMS capable of optimally handling of bidirectional energy transaction with the national grid by scheduling the sources, load and storages for large scale industrial $\mu \mathrm{Gs}$, have not been proposed. Further, EMS communicates with the building owner as well as utility via communication channels. Such wireless or wired links remain under the threat of continuous unauthorized intrusion from external and/or internal intruders that may alter the parameters for instance weather and tariff data resulting in non-optimal schedule of $\mu \mathrm{G}$ components. Non-optimal schedule of industrial process leads to major economic losses. To address such undesirable scenario, a cyber security-based strategy needs to be devised for $\mathrm{I} \mu \mathrm{G}$. This paper proposes two-cored EMS for this class of customers. First core termed as energy layer optimizes energy consumption cost and emission whereas second core termed as security layer secures the communication channel from internal and external intrusion. Such cyber secure communication link masks the EMS to avoid malfunction. The following novel contributions have been made in this paper.

(i) Modeling large scale $\mathrm{I} \mu \mathrm{G}$ containing Internal Combustion Engine (ICE), Fuel Cell (FC), Microturbine (MT), solar PV penal, battery and Electrical Vehicles (EVs) lot as the above contributions have not been taken all these energy carriers simultaneously.

(ii) Devising a strategy to participate in ancillary market service termed as Spinning Reserve (SR).

(iii) Analyzing the impact of presence of EV lot on energy consumption cost and emission.

(iv) Proposing cyber security mechanism in smoothsec software to detect and prevent unlicensed internal and external intrusion.

(v) Performing risk analysis based on Monte Carlo simulations.

The rest of the paper is organized as: section-2 presents the proposed two-cored energy management system for an $\mathrm{I} \mu \mathrm{G}$, section-3 presents first core i.e. energy layer, section-4 presents second core i.e. cyber security layer and section- 5 draws the conclusion.

\subsection{Proposed Two-Cored Energy Management System for Industrial Microgrid}

Proposed two-cored EMS for $\mathrm{I} \mu \mathrm{G}$ has been shown in Fig. 1. In this architecture, load automation layer receives data from customer, network and weather servers. Communication layer consists of a wired or wireless link to transmit data to the BEMS optimization layer. Scheduling layer contains optimization core to generate optimal dispatch signals for components in service layer. Service layer serves 
energy sources, load and storages to attain desired objectives. To provide adequate cyber security intrusion detection and prevention barrier has been placed between data servers and communication channel as well as communication channel and BEMS optimizer.

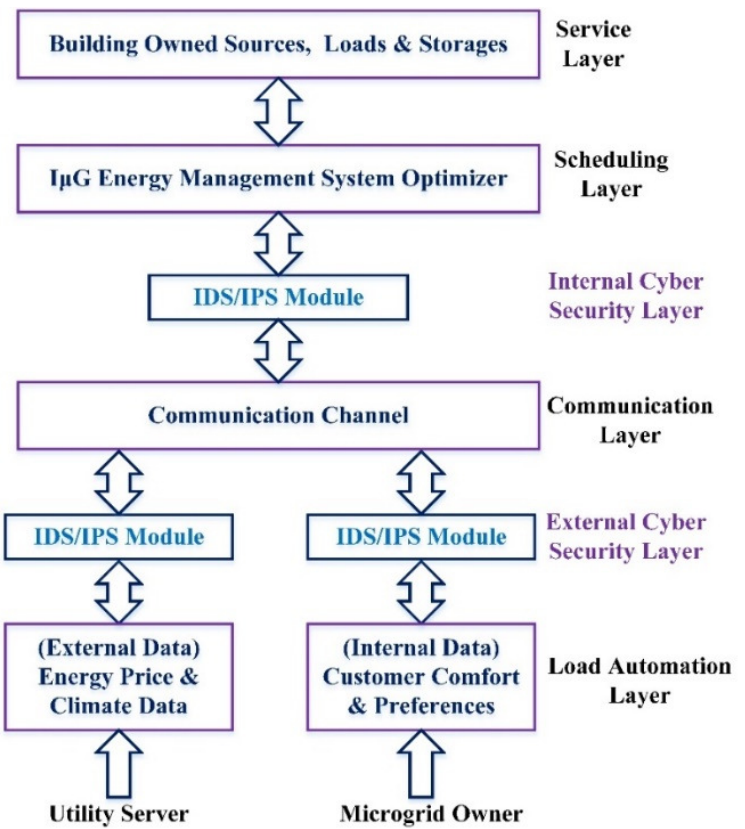

Fig. 1: Proposed Two-Cored Layered Process of BEMS for $\mathrm{I} \mu \mathrm{G}$

\section{FIRST CORE: ENERGY LAYER}

\subsection{Operational Perspective}

Microgrid may contain multiple options such as DR schemes and onsite DERs. Proposed $\mathrm{I} \mu \mathrm{G}$ shown in Fig. 2 has been divided into AC and DC subsections. AC subsection consists of ICE, FC, MT whereas DC subsection contains solar PV penal, battery and EV lot. Both subsections have been physically coupled through energy converters to the national grid at the Point of Common Coupling (PCC). Building owned DERs transform the passive consumer into active prosumer that can sell access energy to the national grid for energy cost and network load reduction. Proposed building takes part in SR market. Spinning reserve equal to $10 \%$ of the load meets the abrupt load variations in the building. Remaining part of SR sells out to the national grid. Energy management system control selects the most inexpensive source from available energy carriers. For instance, the DERs are preferred over the national grid during peak load hours and vice versa during remaining period. Therefore, it may be inferred that as the energy tariff rises, the energy imported from the national grid declines, revealing a non-linear cost-demand relation. Presence of solar energy is entirely time and weather dependent. During daytime, the building energy consumption depends on solar power however load feeds from national grid and other DERs during night. Such uncertain presence of solar irradiance may undesirably affect the performance of the $\mu \mathrm{G}$. Battery and EV lot act as active loads and discharge back into the $\mu \mathrm{G}$ during peak hours to lower the consumption cost. Location of the industrial building has been suitable in such a way that EVs may connect and disconnect with the building quite easily. Microgrid owner signs an agreement with the vehicle owner to charge/discharge them from/into the $\mu \mathrm{G}$. Cost paid to the vehicle owner incorporates the battery degradation charges for compensation.

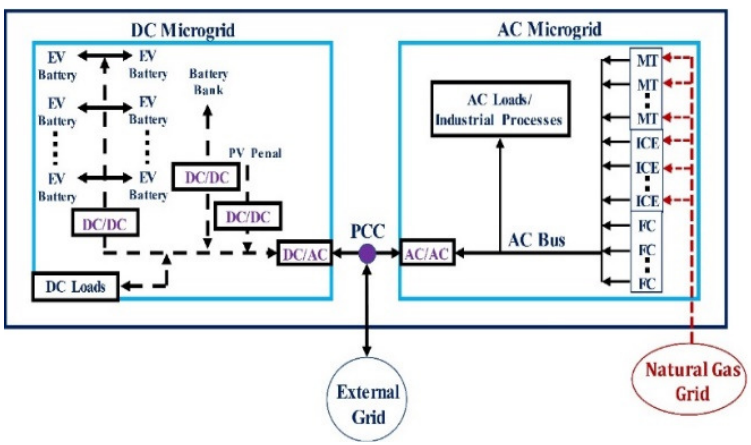

Fig. 2: Proposed Hybrid Industrial Microgrid

\subsection{Implementation of Proposed Control}

Building energy management module resides in the customers premises to provide internal load automation and subsequent energy cost and emission reduction as shown in Fig. 3. The Building Energy Manager (BEM) communicates with the appliances, sources and storages via radio frequency wireless link to take boundary limits of the building components and customer preferences. Currently Bluetooth and Zigbee have been in use to establish the communication link. In response to this an optimal dispatch signal routes back through smart meter via same communication media for optimum dispatch. The BEM also communicates with utility for mutual sharing of relevant information. 


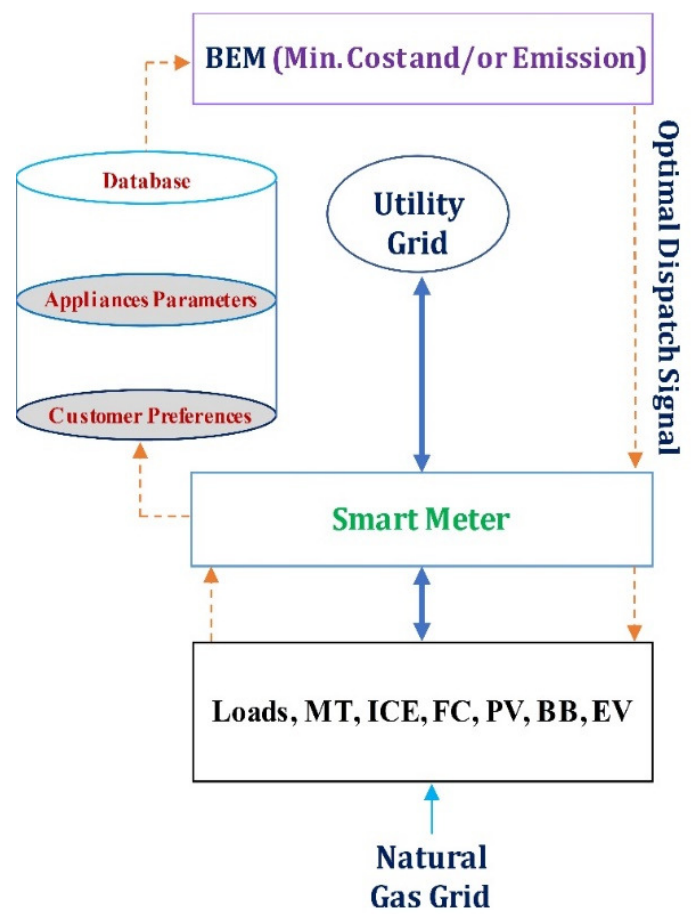

Fig. 3: Implementation details of proposed control

\subsection{Mathematical Modeling of Industrial Microgrid Components}

This section presents the mathematical modeling of the first layer of $\mu \mathrm{G}$ components [20].

\subsubsection{Generation Sources in Industrial Microgrid}

Mathematical modeling of energy generation sources in $\mathrm{I} \mu \mathrm{G}$ is presented as below:

Stationary Storage System: Mathematical model of station battery residing in the building is given below:

$$
\begin{aligned}
& \mathrm{e}_{\text {ses }, \mathrm{i}}(\mathrm{t})=\left(1-\varphi_{\text {ses }, \mathrm{i}}\right) \cdot \mathrm{e}_{\text {ses }, \mathrm{i}}(\mathrm{t}-1)+ \\
& \tau \cdot\left(\mathrm{p}_{\text {ses }, \mathrm{i}}^{\mathrm{chg}}(\mathrm{t}) \cdot \eta_{\text {ses }}^{\text {chg }}-\frac{\mathrm{p}_{\text {ses }, \mathrm{i}}^{\text {dch }}(\mathrm{t})}{\eta_{\text {ses }}^{\text {dch }}}\right)
\end{aligned}
$$

where i, $e_{\text {ses }, \mathrm{i}}(\mathrm{t}), \varphi_{\text {ses, }} \tau, \mathrm{p}_{\text {ses }, \mathrm{i}}^{\text {chd }}, \mathrm{p}_{\mathrm{ses}, \mathrm{i}}^{\mathrm{dch}}, \eta_{\text {ses }}^{\text {chg }}$ and $\eta_{\text {ses }}^{\text {dch }}$ are number of $\mu \mathrm{Gs}$, stored energy in $\mathrm{kWh}$, energy storage losses $(\%)$, time interval (h), charging and discharging power $(\mathrm{kW})$ and charging and discharging efficiencies (\%), respectively.

Upper and lower State of Charge (SOC) limits on battery are as follows:

$\mathrm{SOC}_{\text {ses,min }} \cdot \overline{\mathrm{E}}_{\text {ses }} \leq \mathrm{e}_{\text {ses }, \mathrm{i}}(\mathrm{t}) \leq \mathrm{SOC}_{\text {ses,max }} \cdot \overline{\mathrm{E}}_{\text {ses }}$ where $\mathrm{SOC}_{\mathrm{ses}, \min }, \mathrm{SOC}_{\text {ses,max }}$ and $\overline{\mathrm{E}}_{\text {ses }}$ are minimum and maximum SOC limits and total capacity of energy stored $(\mathrm{kWh})$, respectively.

Initially energy stored will be equal to the value at the end of the scheduling horizon $\mathrm{T}$ as below:

$\mathrm{e}_{\mathrm{ses}, \mathrm{i}}(0)=\mathrm{e}_{\mathrm{ses}, \mathrm{i}}(\mathrm{T})=\mathrm{E}_{\mathrm{ses}, \text { initial }}$

The charging and discharging limits of battery are as follows:

$0 \leq \mathrm{p}_{\text {ses }, \mathrm{i}}^{\text {chg }}(\mathrm{t}) \leq \mathrm{u}_{\text {ses }, \mathrm{i}}^{\text {chg }}(\mathrm{t}) \cdot \overline{\mathrm{P}}_{\text {ses }}$

$0 \leq \mathrm{p}_{\mathrm{ses}, \mathrm{i}}^{\mathrm{dch}} \leq \mathrm{u}_{\mathrm{ses}, \mathrm{i}}^{\mathrm{dch}}(\mathrm{t}) \cdot \overline{\mathrm{P}}_{\text {ses }}$

where $\overline{\mathrm{P}}_{\text {ses }}, \mathrm{u}_{\mathrm{ses}, \mathrm{i}}^{\text {chg }}(\mathrm{t})$ and $\mathrm{u}_{\mathrm{ses}, \mathrm{i}}^{\mathrm{dch}}(\mathrm{t})$ are the maximum storage capacity, charging and discharging operational modes, respectively.

The station batteries cannot be in charging and discharging modes simultaneously as shown below:

$\mathrm{u}_{\text {ses }, \mathrm{i}}^{\text {chg }}(\mathrm{t})+\mathrm{u}_{\text {ses }, \mathrm{i}}^{\mathrm{dch}}(\mathrm{t}) \leq 1$

The charging and discharging start-up flags are as:

$v_{\text {ses }, i}^{\text {chg }}(t) \geq u_{\text {ses,i }}^{\text {chg }}(t)-u_{\text {ses }, i}^{\text {chg }}(t-1)$

$v_{\text {ses }}^{\text {dch }}(t) \geq u_{\text {ses }, i}^{\text {dch }}(t)-u_{\text {ses }, i}^{\text {dch }}(t-1)$

where $\quad v_{\text {ses }, \mathrm{i}}^{\mathrm{chg}}(\mathrm{t}), \mathrm{v}_{\text {ses }, \mathrm{i}}^{\mathrm{dch}}(\mathrm{t}), \mathrm{u}_{\text {ses }, \mathrm{i}}^{\mathrm{chg}}(\mathrm{t})$, and $\mathrm{u}_{\text {ses }, \mathrm{i}}^{\mathrm{dch}}(\mathrm{t})$ are start-up flags for charging and discharging modes, and binary variables representing charging and discharging states, respectively.

The battery operational and maintenance (O\&M) cost is;

$\mathrm{C}_{\text {ses }, \mathrm{i}}(\mathrm{t})=\mathrm{C}_{\text {ses }}^{\mathrm{dg}} \frac{1}{2}\left(\mathrm{v}_{\text {ses }, \mathrm{i}}^{\text {chg }}(\mathrm{t})+\mathrm{v}_{\text {ses }, \mathrm{i}}^{\mathrm{dch}}(\mathrm{t})\right)+\mathrm{C}_{\text {ses }}^{\mathrm{m}} \cdot \overline{\mathrm{E}}_{\text {ses }, \mathrm{i}}(\mathrm{t})(9)$ where $\mathrm{C}_{\mathrm{ses}}^{\mathrm{dg}}$ and $\mathrm{C}_{\mathrm{ses}}^{\mathrm{m}}$ are degradation and O\&M costs.

Electric Vehicle: Stored energy in EVs may be used as a reserve in peak hours or at the time of energy sources are under outage. The energy stored in EVs is expressed as:

$\mathrm{E}_{\text {mes, } \mathrm{i}}(\mathrm{t})=\left(1-\varphi_{\text {mes, }, \mathrm{i}}\right) \cdot \mathrm{e}_{\text {mes, } \mathrm{i}}(\mathrm{t}-1)+$ $\tau \cdot\left(p_{\text {mes }, \mathrm{i}}^{\text {chg }}(\mathrm{t}) \cdot \eta_{\text {mes }, \mathrm{i}}^{\text {chg }}-\frac{\mathrm{p}_{\text {messi }}^{\text {dch }}(\mathrm{t})}{\eta_{\text {mes }}^{\text {dch }}}\right)+E_{\text {mes }, i}^{\text {conn }}(t)-E_{\text {mes }, i}^{\text {disc }}(t)$ 
where $E_{\text {mes }, \mathrm{i}}^{\text {conn }}(t), E_{\text {mes }, \mathrm{i}}^{\text {disc }}(\mathrm{t})$, and $\varphi_{\text {mes }}$ are the energy level stored in EVs connected to and disconnected from the $\mu \mathrm{G}$ at time $\mathrm{t}(\mathrm{kWh})$ and energy losses $(\%)$, respectively.

The minimum and maximum limitations of the energy stored in the EV lot are as follows:

$\mathrm{SOC}_{\text {mes,min, },} \cdot \overline{\mathrm{E}}_{\text {mes }}(\mathrm{t}) \leq \mathrm{e}_{\text {mes,i }}(\mathrm{t}) \leq$

$\mathrm{SOC}_{\text {mes,max }, \mathrm{i}} \cdot \overline{\mathrm{E}}_{\text {mes }}(\mathrm{t})$

where $\mathrm{SOC}_{\text {mes,max,i }}$ and $\mathrm{SOC}_{\mathrm{mes}, \mathrm{min}, \mathrm{i}}$ are the maximum and minimum SOC limits (\%), respectively, while $\overline{\mathrm{E}}_{\text {mes }}(\mathrm{t})$ is maximum energy stored at time $\mathrm{t}$ in $\mathrm{kWh}$.

Connected and disconnected energy capacity may be calculated as follows:

$\overline{\mathrm{E}}_{\text {mes }, \mathrm{i}}(\mathrm{t})=\overline{\mathrm{E}}_{\text {mes }, \mathrm{i}}(\mathrm{t}-1)+\overline{\mathrm{E}}_{\text {mes }, \mathrm{i}}^{\text {conn }}(\mathrm{t})-\overline{\mathrm{E}}_{\text {mes }, \mathrm{i}}^{\text {disc }}(\mathrm{t})$

$\underline{E}_{m e s}(t)=\bar{E}_{m e s, i}(t-1)+\bar{E}_{m e s, i}^{c o n n}(t)-\bar{E}_{m e s, i}^{\text {disc }}(t)$

The EVs charging and discharging constraints are as follows:

$0 \leq \mathrm{p}_{\text {mes }, \mathrm{i}}^{\text {chg }}(\mathrm{t}) \leq \mathrm{u}_{\text {ses }, \mathrm{i}}^{\text {chg }}(\mathrm{t}) \cdot \overline{\mathrm{p}}_{\text {mes }}(\mathrm{t})$

$0 \leq p_{\text {mes }, i}^{\text {dch }}(t) \leq u_{\text {ses }, i}^{d c h}(t) \cdot \bar{p}_{\text {mes }}(t)$

where $\bar{p}_{\text {mes }}(\mathrm{t})$ is maximum power stored $(\mathrm{kW})$ in EV lot that is expressed as:

$\overline{\mathrm{p}}_{\text {mes }, \mathrm{i}}(\mathrm{t})=\left(\overline{\mathrm{p}}_{\text {mes }, \mathrm{i}}(\mathrm{t}-1)+\overline{\mathrm{p}}_{\text {mes }, \mathrm{i}}^{\text {conn }}(\mathrm{t})-\overline{\mathrm{p}}_{\text {mes }}^{\text {disc }}(\mathrm{t})\right)$

The charging and discharging cycles can be expressed as below:

$v_{\text {mes }, i}^{\text {chg }}(t) \geq u_{\text {mes }, i}^{\text {chg }}(t)-u_{\text {mes }, i}^{\text {chg }}(t-1)$

$v_{m e s}^{d c h}(t) \geq u_{m e s, i}^{d c h}(t)-u_{m e s, i}^{d c h}(t-1)$

The O\&M cost of EV lot is modeled as:

$\mathrm{C}_{\text {ses }, \mathrm{i}}(\mathrm{t})=\mathrm{C}_{\text {ses }}^{\mathrm{dg}} \frac{1}{2}\left(\mathrm{v}_{\text {ses }, \mathrm{i}}^{\text {chg }}(\mathrm{t})+\mathrm{v}_{\text {ses }, \mathrm{i}}^{\mathrm{dch}}(\mathrm{t})\right)+$

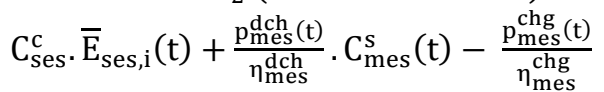

$\mathrm{C}_{\text {mes }}^{\mathrm{d}}(\mathrm{t}), \mathrm{C}_{\text {mes }}^{\mathrm{dg}}, \mathrm{C}_{\text {mes }}^{\mathrm{c}}, \mathrm{C}_{\text {mes }}^{\mathrm{s}}(\mathrm{t})$ and $\mathrm{C}_{\text {mes }}^{\mathrm{d}}(\mathrm{t})$ are the degradation and capacity cost, selling and buying price, respectively.

Solar Energy Generation: Power from the PV panels is given as:

$\mathrm{p}_{\mathrm{pv}, \mathrm{i}}(\mathrm{t})=\Omega_{\mathrm{pv}, \mathrm{i}} \cdot \eta_{\mathrm{pv}, \mathrm{i}} \cdot \mathrm{I}$

where $\Omega_{\mathrm{pv}, \mathrm{i}}, \eta_{\mathrm{pv}, \mathrm{i}}$ and I are the area $\left(\mathrm{m}^{2}\right)$, efficiency $(\%)$ and solar irradiation $\left(\mathrm{kW} / \mathrm{m}^{2}\right)$.

Internal Combustion Engine: The maximum power from the ICE can be expressed as:

$\underline{\mathrm{p}}_{\mathrm{i}, \mathrm{j}} \cdot \mathrm{u}_{\mathrm{i}, \mathrm{j}}(\mathrm{t}) \leq \mathrm{p}_{\mathrm{i}, \mathrm{j}}(\mathrm{t}) \leq \overline{\mathrm{p}}_{\mathrm{i}, \mathrm{j}} \cdot \mathrm{u}_{\mathrm{i}, \mathrm{j}}(\mathrm{t})$

where $\underline{p}_{i, j}, \bar{p}_{i, j}$ andu $u_{i, j}(t)$ are minimum and maximum limits and ON/OFF status of $\mathrm{j}^{\text {th }}$ ICE in $i^{\text {th }} \mu \mathrm{G}$ at time t.

The minimum up and down time specified by an IMG owner using following constraints is as follows:

$\mathrm{v}_{\mathrm{i}, \mathrm{j}}(\mathrm{t})-\mathrm{w}_{\mathrm{i}, \mathrm{j}}(\mathrm{t})=\mathrm{u}_{\mathrm{i}, \mathrm{j}}(\mathrm{t})-\mathrm{u}_{\mathrm{i}, \mathrm{j}}(\mathrm{t}-1)$

$v_{i, j}(t)+w_{i, j}(t) \leq 1$

$\sum_{s=t-U P_{i, j}+1}^{\mathrm{t}} \mathrm{v}_{\mathrm{i}, \mathrm{j}, \mathrm{s}} \leq \mathrm{u}_{\mathrm{i}, \mathrm{j}}(\mathrm{t})$

$\sum_{s=t-D N_{i, j}+1}^{t} W_{i, j, s} \leq 1-u_{i, j}(t)$

where $v_{i, j}(t), w_{i, j}(t)$ are the flags while $U_{i, j}$ and $D_{i, j}$ are the up and down times.

The ramp rates of ICE are expressed as:

$$
\begin{gathered}
p_{i, j}(t)-p_{i, j}(t-1) \leq R_{i, j}^{U P} \cdot u_{i, j}(t-1)+R_{i, j}^{S U}\left(1-u_{i, j}(t-1)\right), \\
\forall t \in[2, T](26) \\
p_{i, j}(t)-p_{i, j}(t-1) \leq R_{i, j}^{D N} \cdot u_{i, j}(t-1)+R_{i, j}^{S D}\left(1-u_{i, j}(t-1)\right), \\
\forall t \in[2, T] \quad(27)
\end{gathered}
$$

where $R_{i, j}^{U P}, R^{D N}, R_{i, j}^{S U}$ and $R_{i, j}^{S U}$ are ramp up, ramp down, start up and shutdown (kW/h) limits respectively.

Engines share the load. The energy sharing constraints are modelled as follows:

$\begin{array}{ll}\frac{p_{i, j}(t)}{\bar{p}_{i, j}} \leq r+\left(1-u_{i}(t)\right) \cdot M & \forall i, j, t \\ \frac{p_{i, j}(t)}{\bar{p}_{i, j}} \geq r+\left(u_{i}(t)-1\right) \cdot M & \forall i, j, t\end{array}$

where $r$ and $\mathrm{M}$ are load sharing ratio and large positive number. The value of $r$ varies between 0 and 1 . 
O\&M cost (\$) contains fixed $\left(\mathrm{A}_{\mathrm{i}, \mathrm{j}}\right)$, fuel $\left(\mathrm{B}_{\mathrm{i}, \mathrm{j}}\right)$, startup $\left(\mathrm{C}_{\mathrm{i}, \mathrm{j}}^{\mathrm{SU}}\right)$, shutdown $\left(\mathrm{C}_{\mathrm{i}, \mathrm{j}}^{\mathrm{SD}}\right)$ and maintenance $\left(\mathrm{C}_{\mathrm{i}, \mathrm{j}}^{\mathrm{om}}\right)$ costs and conversion efficiencies $(\eta)$ as follows:

$C_{i, j}(t)=A_{i, j}+B_{i, j} \cdot \frac{P_{i, j}(t)}{\eta_{i}}+v_{i, j}(t) \cdot C_{i, j}^{S U}+w_{i, j}(t) \cdot C_{i, j}^{S D}+C_{i, j}^{o m} \cdot \bar{p}_{i, j}$

Micro Turbines: The cost expression for MT is:

$C_{i, m}(t)=A_{i, m}+B_{i, m} \cdot \frac{P_{i, m}(t)}{\eta_{m}}+v_{i, m}(t) \cdot C_{i, m}^{S U}+w_{i, m}(t) \cdot C_{i, m}^{S D}+$

$$
\mathrm{C}_{\mathrm{i}, \mathrm{m}}^{\mathrm{om}} \cdot \overline{\mathrm{p}}_{\mathrm{i}, \mathrm{m}}
$$

Fuel Cell: Fuel cell provides base load due to its high starting time. The operational cost can be expressed as:

$$
\begin{aligned}
C_{i, f}(t)= & B_{i, f} \cdot \frac{P_{i, f}(t)}{\eta_{f}}+v_{i, f}(t) \cdot C_{i, f}^{S U}+w_{i, f}(t) \cdot C_{i, f}^{S D}+ \\
& C_{i, f}^{o m} \cdot \bar{p}_{i, f}
\end{aligned}
$$

\subsubsection{Maximum Power Flow Limit Between Microgrid and National Grid}

The $\mathrm{I} \mu \mathrm{G}$ can operate grid-connected as well as in islanded modes. In on grid connected mode, it takes part in SR market and to support utility.

Maximum $\mathrm{I} \mu \mathrm{G}$ power demand can be expressed as:

$p^{d c} \geq p_{i, g}(t)$

where $\mathrm{p}^{\mathrm{dc}}$ and $\mathrm{p}_{\mathrm{i}, \mathrm{g}}(\mathrm{t})$ are required maximum power $(\mathrm{kW})$ for $\mathrm{I} \mu \mathrm{G}$ and power trade, respectively.

Spinning Reserve: To avoid stability issues due to unexpected variation in load, SR equal to $10 \%$ of the total building load will always be available for internal usage. The SR in excess of $10 \%$ will be sold out to utility.

Grid Connected Mode: Microgrid procures/exports energy from/to the utility grid.

$\sum_{\mathrm{i}=1}^{\mathrm{N}_{\mathrm{i}}} \sum_{\mathrm{j}=1}^{\mathrm{N}_{\mathrm{j}}} \mathrm{p}_{\mathrm{i}, \mathrm{j}}(\mathrm{t})+\sum_{\mathrm{i}=1}^{\mathrm{N}_{\mathrm{i}}} \sum_{\mathrm{m}=1}^{\mathrm{N}_{\mathrm{m}}} \mathrm{p}_{\mathrm{i}, \mathrm{m}}(\mathrm{t})+$

$\sum_{\mathrm{i}=1}^{\mathrm{N}_{\mathrm{i}}} \sum_{\mathrm{m}=1}^{\mathrm{N}_{\mathrm{f}}} \mathrm{p}_{\mathrm{i}, \mathrm{f}}(\mathrm{t})+\mathrm{p}_{\mathrm{i}, \mathrm{pv}}(\mathrm{t})+\mathrm{p}_{\mathrm{i}, \mathrm{g}}(\mathrm{t})+\mathrm{p}_{\mathrm{i}, \mathrm{ses}}^{\mathrm{dch}}(\mathrm{t})+\mathrm{p}_{\mathrm{i}, \mathrm{mes}}^{\mathrm{dch}}(\mathrm{t})=$

$p_{i, D}(t)+p_{i, s e s}^{\text {chg }}(t)+p_{i, m e s}^{\text {chg }}(t)$

where $P_{i, g}(t)$ and $P_{i, D}(t)$ are energy trade and $I \mu G$ load demand $(\mathrm{kW})$, respectively.

Grid Connection: The utility grid imposes energy transaction limits that are modelled as:

$-\underline{\mathrm{p}}_{\mathrm{i}, \mathrm{g}} \leq \mathrm{p}_{\mathrm{i}, \mathrm{g}}(\mathrm{t}) \leq \overline{\mathrm{p}}_{\mathrm{i}, \mathrm{g}}$ where $-p_{i, g}$ and $\bar{p}_{i, g}$ are the minimum and maximum limits $(\mathrm{kW})$ respectively.

Ancillary Services: Mathematical representation of $\mathrm{SR}$ is represented as:

$\mathrm{SR}=\sum_{\mathrm{i}=1}^{\mathrm{N}_{\mathrm{i}}} \sum_{\mathrm{j}=1}^{\mathrm{N}_{\mathrm{j}}}\left(\overline{\mathrm{p}}_{\mathrm{i}, \mathrm{j}} \mathrm{u}_{\mathrm{i}, \mathrm{j}}(\mathrm{t})-\mathrm{p}_{\mathrm{i}, \mathrm{j}}(\mathrm{t})\right)+\sum_{\mathrm{i}=1}^{\mathrm{N}_{\mathrm{i}}} \sum_{\mathrm{m}=1}^{\mathrm{N}_{\mathrm{m}}}\left(\overline{\mathrm{p}}_{\mathrm{i}, \mathrm{m}} \cdot \mathrm{u}_{\mathrm{i}, \mathrm{m}}(\mathrm{t})-\right.$
$\left.\mathrm{p}_{\mathrm{i}, \mathrm{m}}(\mathrm{t})\right)+\sum_{\mathrm{i}=1}^{\mathrm{N}_{\mathrm{i}}} \sum_{\mathrm{m}=1}^{\mathrm{N}_{\mathrm{f}}}\left(\overline{\mathrm{p}}_{\mathrm{i}, \mathrm{f}} \cdot \mathrm{u}_{\mathrm{i}, \mathrm{f}}(\mathrm{t})-\mathrm{p}_{\mathrm{i}, \mathrm{f}}(\mathrm{t})\right)+\mathrm{p}_{\mathrm{i}, \mathrm{mes}}^{\mathrm{SR}}(\mathrm{t})+\mathrm{p}_{\mathrm{i}, \mathrm{ses}}^{\mathrm{SR}}(\mathrm{t})-$
0.1. $\mathrm{p}_{\mathrm{i}, \mathrm{D}}$

where $\mathrm{p}_{\mathrm{SR}}(\mathrm{t}), \mathrm{p}_{\mathrm{i}, \mathrm{mes}}^{\mathrm{SR}}(\mathrm{t})$ and $\mathrm{p}_{\mathrm{i}, \mathrm{ses}}^{\mathrm{SR}}(\mathrm{t})$ are the SR from I $\mu \mathrm{G}$ DERs, MES and SES respectively.

Spinning reserve from SES and MES is expressed as:

$p_{i, \text { ses }}^{\text {SR }}(t) \leq \bar{p}_{i, \text { ses }}-p_{i, \text { ses }}^{\text {dch }}(t)$

$\mathrm{p}_{\mathrm{i}, \text { mes }}^{\text {SR }}(\mathrm{t}) \leq \overline{\mathrm{p}}_{\mathrm{i}, \mathrm{mes}}-\mathrm{p}_{\mathrm{i}, \mathrm{mes}}^{\mathrm{dch}}(\mathrm{t})$

Energy consumption cost for $\mathrm{I} \mu \mathrm{G}$ are expressed as:

$\operatorname{cst}=p^{d c} \cdot C_{g}^{d c}+\sum_{t=1}^{\tau} \tau\left[-p_{S R}(t) \cdot C_{g}^{S R}(t)+p_{g}(t) \cdot C_{g}^{s}(t)+\right.$

$\sum_{j=1}^{N_{j}} C_{i, j}(t)+\sum_{m=1}^{N_{m}} C_{i, m}(t)+\sum_{f=1}^{N_{f}} C_{i, f}(t)+C_{p v}^{o m}+C_{s e s}(t)+$

$\left.\mathrm{C}_{\text {mes }}(\mathrm{t})\right]$

where $\mathrm{C}_{\mathrm{g}}^{\mathrm{dg}}(\mathrm{t}), \mathrm{C}_{\mathrm{g}}^{\mathrm{s}}(\mathrm{t}), \mathrm{C}_{\mathrm{g}}^{\mathrm{SR}}(\mathrm{t})$ and cst are peak demand charges (\$/day) and energy charges (\$/day) for utility grid, SR cost (\$/day) and power consumption cost (\$/day), respectively.

Emissions of the $\mathrm{I} \mu \mathrm{G}$ in $\mathrm{kg} / \mathrm{day}$ are:

ems $=\sum_{\mathrm{t}=1}^{\mathrm{T}} \tau\left[\sum_{\mathrm{j}=1}^{\mathrm{N}_{\mathrm{j}}} \xi_{\mathrm{i}, \mathrm{j}}^{\mathrm{GHG}} \cdot \frac{\mathrm{p}_{\mathrm{i}, \mathrm{j}}(\mathrm{t})}{\eta_{\mathrm{i}, \mathrm{j}}}+\sum_{\mathrm{m}=1}^{\mathrm{N}_{\mathrm{m}}} \xi_{\mathrm{i}, \mathrm{m}}^{\mathrm{GHG}} \cdot \frac{\mathrm{p}_{\mathrm{i}, \mathrm{m}}(\mathrm{t})}{\eta_{\mathrm{i}, \mathrm{m}}}+\right.$
$\left.\sum_{\mathrm{f}=1}^{\mathrm{N}_{\mathrm{f}}} \xi_{\mathrm{f}, \mathrm{m}}^{\mathrm{GHG}} \cdot \frac{\mathrm{p}_{\mathrm{f}, \mathrm{m}}(\mathrm{t})}{\eta_{\mathrm{f}, \mathrm{m}}}+\xi_{\mathrm{i}, \mathrm{g}}^{\mathrm{GHG}} \cdot \mathrm{p}_{\mathrm{i}, \mathrm{g}}(\mathrm{t})+\left(\mathrm{e}_{\mathrm{mes}}(\mathrm{t})-\mathrm{e}_{\mathrm{mes}}(0) \cdot \xi_{\mathrm{mes}, \mathrm{i}}^{\mathrm{GHG}}\right)\right]$

$\xi_{\mathrm{i}}^{\mathrm{GHG}}$ shows the rate of GHG emission in $\mathrm{kg} / \mathrm{h}$.

\subsection{Solution Methodology, Results and Discussion}

Flower Pollination Algorithm (FPA) shows superiority in terms of locating the global optimum and speed with low functional complexity over fuzzy logic, cuckoo search, particle swarm optimization, differential evolution particle swarm optimization, random search and neural network [20]. The proposed mathematical framework is a linear optimization model solved in MATLAB. Keeping such efficient 
performance in view the proposed framework has been solved in FPA. Mathematical structure of FPA may be found in [20]. The flowchart of the algorithm is provided in Fig. 4. Switching probability, lambda, alpha and number of iterations in our cases are $0.8,1.5$, 0.1 and 1000, respectively. Since FPA processes the information randomly therefore the best result in 10runs is presented in case studies.

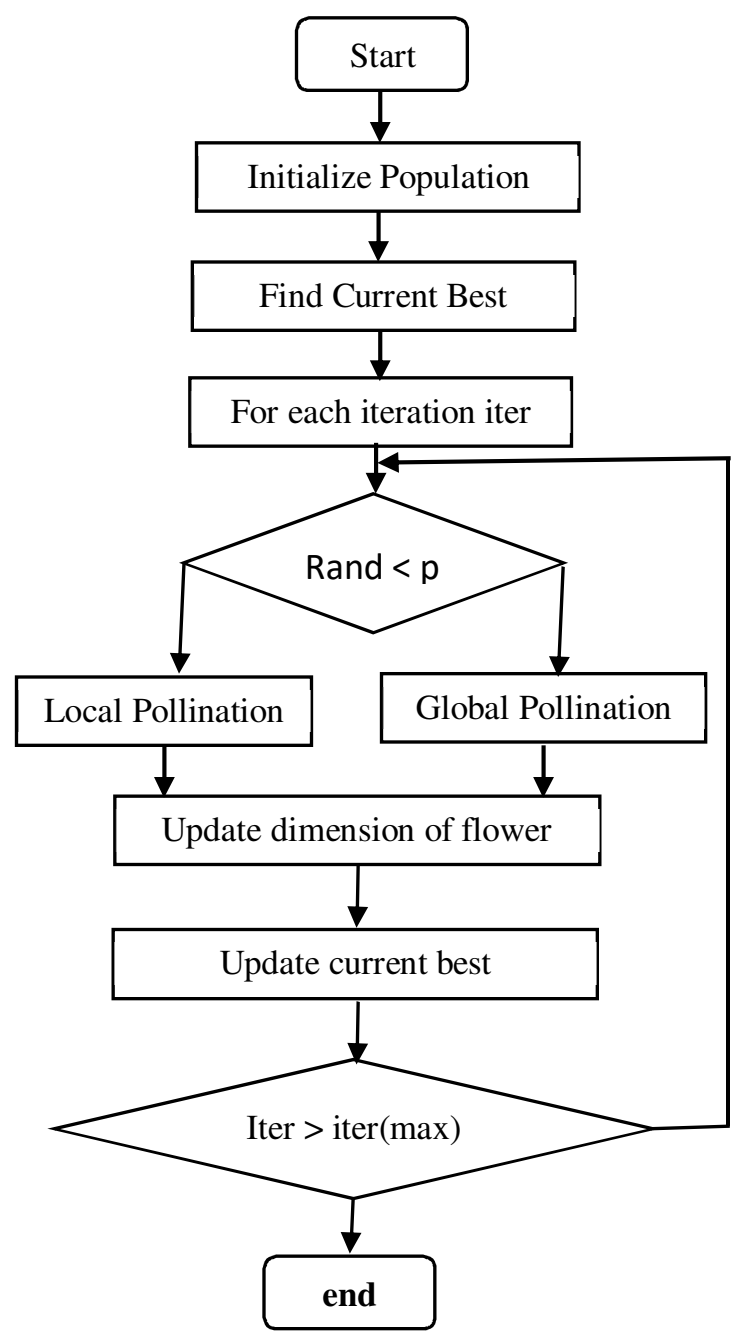

Fig. 4: Flower Pollination Algorithm

This following section discusses the results of first core: the energy layer.

\subsubsection{Proposed Energy Layer Results and Discussion}

The hourly energy demand of each sub-process in a cement factory situated in Taxila, Pakistan, is shown in Fig. 5. Manufacturing facility functions daily in two shifts of $12 \mathrm{~h}$ each. Load pattern reveals that the most of processes such as finishing work carries out during day time.

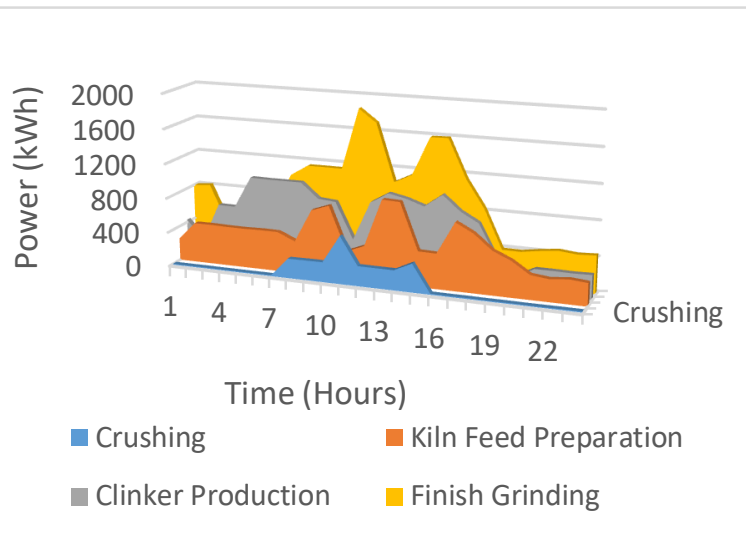

Fig. 5: Hourly Energy Demand of Element Plant

The peak demand price, energy and SR charges, total and net EV capacity connected to the $\mathrm{I} \mu \mathrm{G}$, parameters of the $\mathrm{I} \mu \mathrm{G}$, DERs, and energy storages are taken from the study by Raza and Malik [20]. Table I shows that subcases 1(i), 2(i), 3(i), 4(i) optimize total energy cost of the I $\mu \mathrm{G}$. Likewise 1(ii), 2(ii), 3(ii), 4(ii) reduce the total emission. Case-5 analyses the bi-objective scenario minimizing emission and cost concurrently.

Case-1: In subcases 1(i) and 1(ii) SR and EV lot are not considered. As can be witnesses in Table 2 that total energy cost of the $\mathrm{I} \mu \mathrm{G}$ reduces down to $-273.041 \$$ whereas emission minimizes to $5122.1 \mathrm{~kg}$. Reason of decline in cost has been the presence of onsite generation. Results encourage the building owners to install distributed generation for transformation from passive consumers into active prosumers.

Case-2: In subcases 2(i) and 2(ii) building takes part in ancillary services such as the SR market, however does not consider the EV lot. For both subcases, total energy cost of $\mu \mathrm{G}$ and emission are $-414.523 \$$, $6681.6 \mathrm{~kg}$ and $391.8721 \$, 5615.2 \mathrm{~kg}$, respectively. As may be witnessed that total energy cost of $\mu \mathrm{G}$ minimizes by $51.8172 \%$ from $-273.041 \$$ to $-414.523 \$$. Similarly, GHG emission reduces by $1.8682 \%$ in subcase 2(ii) compared to 1(ii). Results prove a fact that presence of SR bilaterally benefits the microgrid owner in terms of energy cost reduction and environment. Main reason of improvement in performance has been that SR acts in the form of 


\begin{tabular}{|c|c|c|c|c|c|c|c|}
\hline \multicolumn{8}{|c|}{ Table I: Details of Case Studies } \\
\hline \multicolumn{2}{|c|}{ Cases Studies } & $\begin{array}{c}\text { Utility } \\
\text { Grid }\end{array}$ & $\begin{array}{c}\text { Stationary } \\
\text { Energy }\end{array}$ & $\begin{array}{l}\text { Mobile } \\
\text { Energy }\end{array}$ & $\begin{array}{c}\text { Onsite } \\
\text { Generation }\end{array}$ & $\begin{array}{l}\text { Spinning } \\
\text { Reserves }\end{array}$ & $\begin{array}{l}\text { Objective } \\
\text { Function }\end{array}$ \\
\hline \multirow{8}{*}{$\begin{array}{c}\text { Single } \\
\text { Objective } \\
\text { I } \mu \mathrm{G}\end{array}$} & Case-1 (i) & $\checkmark$ & $\checkmark$ & $x$ & $\checkmark$ & $x$ & Cost \\
\hline & $\begin{array}{l}\text { Case-1 } \\
\text { (ii) }\end{array}$ & $\checkmark$ & $\checkmark$ & $x$ & $\checkmark$ & $x$ & Emission \\
\hline & Case-2 (i) & $\checkmark$ & $\checkmark$ & $x$ & $\checkmark$ & $\checkmark$ & Cost \\
\hline & $\begin{array}{l}\text { Case-2 } \\
\text { (ii) }\end{array}$ & $\checkmark$ & $\checkmark$ & $x$ & $\checkmark$ & $\checkmark$ & Emission \\
\hline & Case-3 (i) & $\checkmark$ & $\checkmark$ & $\checkmark$ & $\checkmark$ & $x$ & Cost \\
\hline & $\begin{array}{l}\text { Case-3 } \\
\text { (ii) }\end{array}$ & $\checkmark$ & $\checkmark$ & $\checkmark$ & $\checkmark$ & $x$ & Emission \\
\hline & Case-4 (i) & $\checkmark$ & $\checkmark$ & $\checkmark$ & $\checkmark$ & $\checkmark$ & Cost \\
\hline & $\begin{array}{l}\text { Case-4 } \\
\text { (ii) }\end{array}$ & $\checkmark$ & $\checkmark$ & $\checkmark$ & $\checkmark$ & $\checkmark$ & Emission \\
\hline $\begin{array}{c}\text { Bi- }^{-} \\
\text {Objective } \\
\text { I } \mu \mathrm{G}\end{array}$ & Case-5 & $\checkmark$ & $\checkmark$ & $\checkmark$ & $\checkmark$ & $\checkmark$ & $\begin{array}{c}\text { Cost }+ \\
\text { Emission }\end{array}$ \\
\hline
\end{tabular}

\begin{tabular}{|c|c|c|c|c|c|c|c|c|c|c|}
\hline \multicolumn{11}{|c|}{ Table 2: Comparison of Case Studies } \\
\hline \multicolumn{2}{|c|}{$\begin{array}{l}\text { Objective } \\
\text { Function }\end{array}$} & \multirow{2}{*}{$\begin{array}{c}\text { Energy } \\
\text { Cost } \\
(\$)\end{array}$} & \multirow{2}{*}{$\begin{array}{c}\text { On site } \\
\text { Gen. } \\
\text { Cost } \\
(\$)\end{array}$} & \multirow{2}{*}{$\begin{array}{c}\text { Net } \\
\text { battery } \\
\text { Cost } \\
(\$)\end{array}$} & \multirow{2}{*}{$\begin{array}{c}\text { Net EV } \\
\text { Cost } \\
(\$)\end{array}$} & \multirow{2}{*}{$\begin{array}{c}\text { Total } \\
\mathrm{I} \mu \mathrm{G} \\
\mathrm{SR} \\
(\$)\end{array}$} & \multirow{2}{*}{$\begin{array}{c}\text { Battery } \\
\text { SR } \\
\text { Value } \\
(\$)\end{array}$} & \multirow{2}{*}{$\begin{array}{c}\text { EV SR } \\
\text { Value } \\
(\$)\end{array}$} & \multirow{2}{*}{$\begin{array}{c}\text { Total } \\
\text { Building } \\
\text { Cost } \\
(\$)\end{array}$} & \multirow{2}{*}{$\begin{array}{c}\text { Total } \\
\text { Emission } \\
(\mathrm{kg})\end{array}$} \\
\hline Cases & $\begin{array}{c}\text { Sub- } \\
\text { Cases }\end{array}$ & & & & & & & & & \\
\hline Case-1 & (i) & -10248 & 9840.1 & 134.432 & 0 & 0 & 0 & 0 & -136.52 & 5897.8 \\
\hline & (ii) & -9518.6 & 9367.4 & 134.428 & 0 & 0 & 0 & 0 & -8.35 & 5722.1 \\
\hline Case-2 & (i) & -5286.2 & 6867.3 & 134.42 & 0 & -2130.1 & -1459.9 & 0 & -207.26 & 6681.6 \\
\hline & (ii) & -8151.2 & 8424.3 & 134.418 & 0 & -15.9 & -427.1 & 0 & 195.93 & 5615.2 \\
\hline Case-3 & (i) & -9733.4 & 9481.8 & 134.434 & 254.2061 & 0 & 0 & 0 & 68.50 & 7217.2 \\
\hline & (ii) & -8893.8 & 9289.4 & 134.428 & 260.4638 & 0 & 0 & 0 & 395.24 & 5792.6 \\
\hline Case-4 & (i) & -5351.3 & 6976.3 & 134.426 & 172.0217 & -3339.6 & -1242 & -1447.1 & -704.05 & 6808.5 \\
\hline & (ii) & -9851.4 & 9496.9 & 134.418 & 160.5549 & $\begin{array}{l}-899.2 \\
\end{array}$ & -103.9 & -870.4 & -30.83 & 5302.8 \\
\hline Case-5 & -4840.3 & 71749 & 134.426 & 148.787 & -2595 & $\begin{array}{l}-791.8 \\
\end{array}$ & -1250.4 & -11.40 & 6097.8 & \\
\hline
\end{tabular}

energy reserve for $\mu \mathrm{G}$ during high tariff hours thereby minimizing total energy cost of the costumer and environmental pollution. Furthermore, SR serves as a source of energy for building load during loss of enhancing the resilience of $\mu \mathrm{G}$. Loss of energy carrier may occur due to natural disasters such as floods, hurricanes, tornados, earth quakes, tsunami and harsh weather changes and technical faults such as outages on generation, transmission and distribution system.

Cae-3: In sucases 3(i) and 3(ii) building does not participate in the SR market, however, contains EV lot. Total energy cost of $\mu \mathrm{G}$ increases in 3(i) compared to the subcases 1(i) and 2(i). Similarly, emission in subcase 3(ii) increases in comparison to subcases 1(ii) and 2(ii). Results unravel that energy storage in the form of EV lot without building's participation in SR market has unfavorable outcome. These results entice the buildings to participate in ancillary services to feed energy carrier or abrupt increase in demand, thus internal and external energy networks to earn revenue and attain green energy targets.

Case-4: The subcases 4(i) and 4(ii) consider SR and EV lot. Microgrid earns maximum revenue of $-1408.1 \$$ in 4(i) with the lowest emission $5302.8 \mathrm{~kg}$ per day in subcase 4(ii). Comparison of case-2 and case-4 demonstrate that concurrent presence of EV lot and SR plays important role in total energy cost of $\mu \mathrm{G}$ and emission minimization.

Case 5: Case 5 is bi-objective with SR and EV lot. Total energy cost and emission of the building rise compare to subcases 4(i) and 4(ii) respectively. Figs. 
6-9 show $\mu \mathrm{G}$ energy sources, $\mu \mathrm{G}$ load and transections with national grid, $\mu \mathrm{G}$ spinning reserve and Pareto optimal sets [21] of cost and emission.

\subsubsection{Risk Analysis Using Monte Carlo Simulation}

To analyze the impact of random solar PV presence and unpredictable electric and NG outages, risk is carried out using Monte Carlo simulations [30].

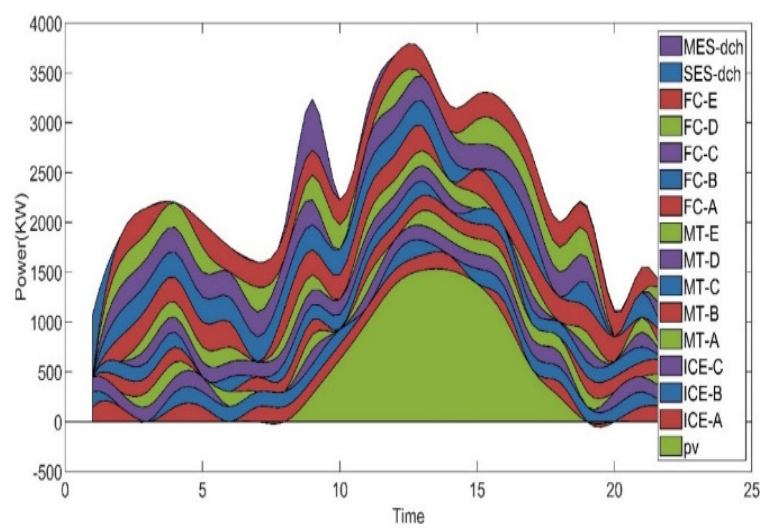

Fig. 5: Industrial Microgrid Energy Resources

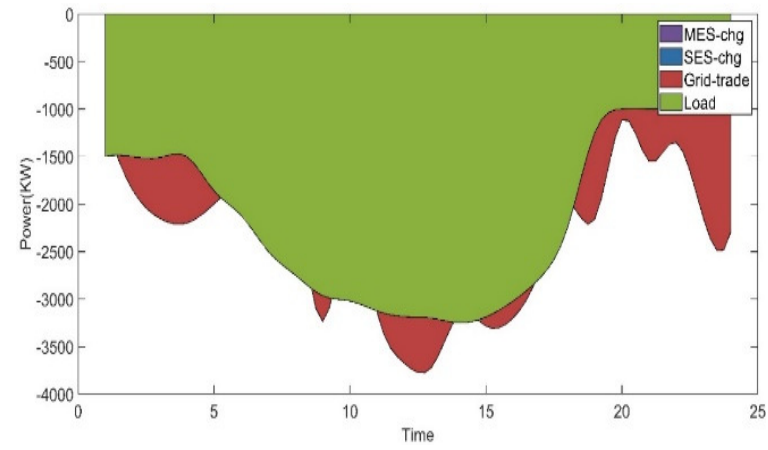

Fig. 6: Industrial Microgrid Load and Transactions with National Grid

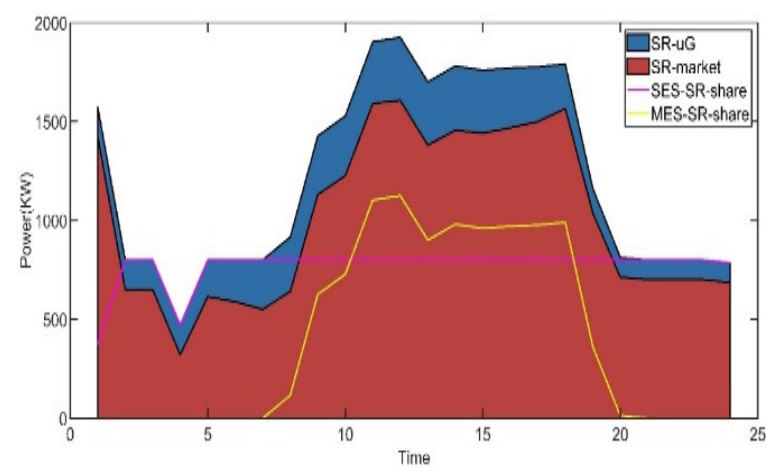

Fig. 7: I $\mu$ g Spinning Reserve: Propionate Share of Energy Carriers

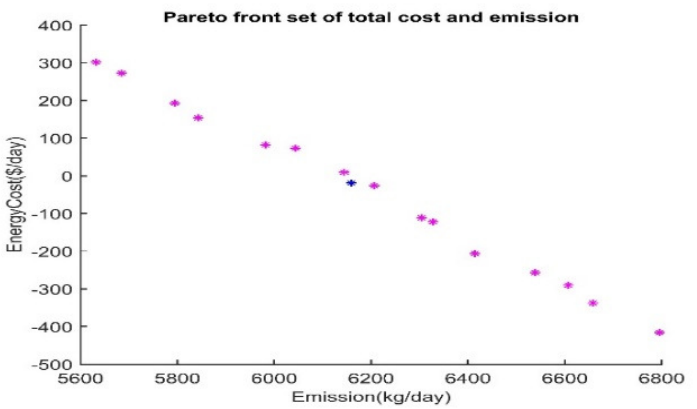

Fig. 8: Pareto Optimal Sets of Cost and Emission

Probability density function for network outages is modeled as exponential distribution [31]. To improve the accuracy, large number of scenarios are generated. For this purpose, 8000 outage scenarios are generated using two state Markov chain process [32]. To lessen the computations, scenarios are reduced to 100 using K-Means [33] technique. To generate random scenarios of solar irradiance, normal distribution [34] is used. Fast forward technique [35] is used to create 8000 scenarios and subsequently reduced to 100 by KMeans technique.

Results show that random solar PV presence has more meaningful impact on building energy cost and emission. Witnessing these outcomes, random solar $\mathrm{PV}$ presence is ranked as 1 . To alleviate such situation, electric and thermal energy storage devices are suggested to the utility owners.

\section{SECOND CORE: CYBER SECURITY LAYER}

Energy management system controls customer's stakes such as energy consumption cost and emission by taking tariff, weather data and customer preferences as input through communication links between user and EMS as well as EMS and utility. User-EMS link may be developed by using either Bluetooth or Zigbee. Any intrusion to this channel to change the information may be termed as internal intrusion, however, unauthorized access to EMSutility link is termed as external intrusion. Optimal operation of EMS depends on the accuracy of information flowing to the control module. However, external or/and internal intruders may change the accuracy resulting in an in-optimal scheduling of $\mu \mathrm{G}$ components. To overcome this threat, a cyber security 


\begin{tabular}{|c|c|c|c|c|c|c|c|}
\hline \multicolumn{8}{|c|}{ Table 3: Risk Analysis in the Presence of Random Parameters } \\
\hline \multirow{2}{*}{$\begin{array}{c}\text { Case } \\
\text { Studies }\end{array}$} & \multirow{2}{*}{$\begin{array}{c}\text { Random } \\
\text { Parameters }\end{array}$} & \multicolumn{2}{|c|}{ Standard Deviation } & \multicolumn{2}{|c|}{ Percentage Change (\%) } & \multirow{2}{*}{$\begin{array}{c}\text { Parameter } \\
\text { Ranking }\end{array}$} & \multirow{2}{*}{$\begin{array}{c}\text { Suggested } \\
\text { Measures for } \\
\text { Utilities }\end{array}$} \\
\hline & & $\begin{array}{l}\text { Total } \mu \mathrm{G} \\
\text { Cost }(\$)\end{array}$ & $\begin{array}{c}\text { Emission } \\
(\mathrm{kg})\end{array}$ & Cost & Emission & & \\
\hline \multirow[b]{2}{*}{5} & $\begin{array}{c}\text { Electric + NG } \\
\text { Outages }\end{array}$ & 304.09 & 275.012 & \multirow[b]{2}{*}{$+105.71 \%$} & \multirow[b]{2}{*}{+74.14} & 2 & \multirow[b]{2}{*}{$\begin{array}{c}\text { Installation of } \\
\text { Energy Storage } \\
\text { Devices }\end{array}$} \\
\hline & $\begin{array}{c}\text { Electric + NG } \\
\text { Outages with } \\
\text { Random Solar } \\
\text { PV }\end{array}$ & 625.54 & 478.91 & & & 1 & \\
\hline
\end{tabular}

mechanism is developed to detect and prevent unlicensed internal access.

Literature [22] shows that there are various types of attack named as: (a) Denial-of-Service (DoS), (b) Man-in-the-Middle (MitM), (c) drive-by attack, (d) password attack, (e) Structured Query Language (SQL) injection attack and (f) zero-day exploit etc.

In denial-of-service attack [23], individual or multiple attacker(s) transmit flood of information to a target server/ router either from within customer premises or from outside. Under such conditions, system either crashes or denies service to the authorized user resulting in inconvenience to the customers and malfunction of EMS module. In man-in-the-middle attack [24], an unlicensed intruder intermeddles or eavesdrops the communicating parties to alter the information, thereby, modifying the actual meaning of the message. Such an attacker may reside inside or outside of the $\mu \mathrm{G}$. Under such condition, EMS may receive erroneous energy prices from utility server (external intruder), weather data from meteorology department (external intruder) and customer preferences (internal intruder). In drive-by attack [25], either external or internal intruder accesses and install a malicious malware in EMS module. Under such situations, intruder controls the EMS to improperly schedule the $\mu \mathrm{G}$ components and reach in-optimal decisions. Under password attacks [26], internal or external intruders decrypt the password to gain access to the EMS to alter its operational behavior to reach in-optimal solution. In SQL injection attack [27], intruder access the database to act as system administrator and may either change or wipeout the entire data. In zero-day exploit [28], cybercriminal scans the weaknesses or vulnerability of the EMS software and develops tools to exploit them.
Among the above-mentioned attacks, DoS and change of password have been the most commonly occurring [29]. Therefore, this paper proposes a cyber security technique to detect and prevent these attacks for secure operation of EMS. Literature shows [18] that internal intrusion proves more threatening compared to external attacks therefore scope of devised technique has been limited to secure EMS from internal intrusions within local area network of the $\mu \mathrm{G}$. The technique of covering both internal and external intrusion will be devised in future. Rest of this subsection discusses the implementation details of devised technique.

For validation of proposed IDS/IPS scheme, system shown in Fig. 10 is designed in smooth-sec software [14]. Smooth-sec functions in two modes: 1) as sensor representing the cyber security part of EMS module and 2) as console. Energy management system acts as a target of an attacker, whereas, console functions as an antivirus capable of detecting and eliminating the attack. Both sensor and console having different IP addresses reside in two separate computers as shown in Figs.10-12. The computer shown in Fig. 10 with IP address 10.8.20.60 acts as an internal intruder/attacker. Linux based operating system termed as Kali Linux 4.18.10 is installed to generate malware data packets as shown in Fig. 13. The window shown in Fig. 14 displays the types of attack named as "open with telnet (protocol mismatch attack)" and "open with ssh client as root (password mismatch attack)".

The proposed technique has three steps: attack, detection and prevention as shown in Fig. 15. In the first step, an intruder launches an attack at the input ports of EMS module. In second step, the IDS/IPS residing in EMS continuously monitors data parts to differentiate between normal and abnormal packets. 


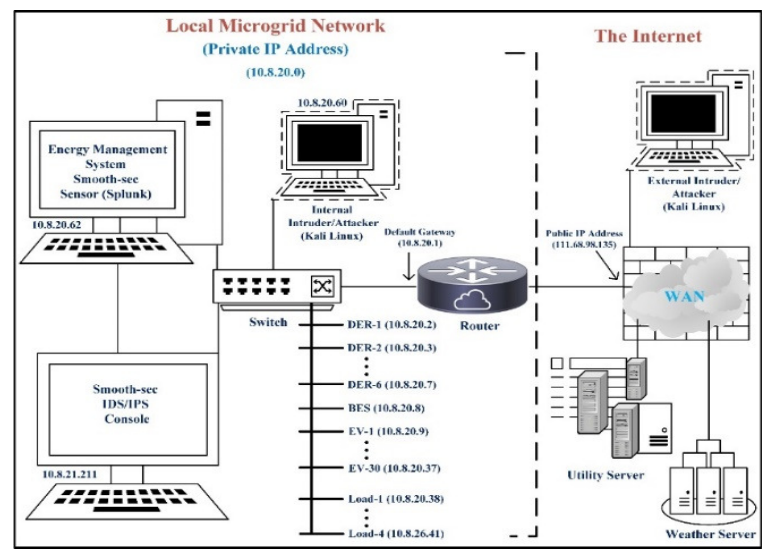

Fig. 9: Proposed Industrial Microgrid Network Topology

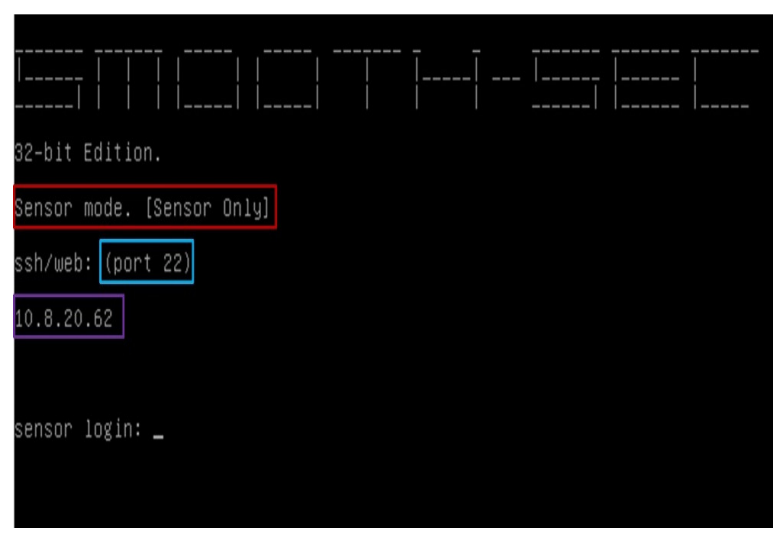

Fig. 10: Smooth-Sec installed as Sensor

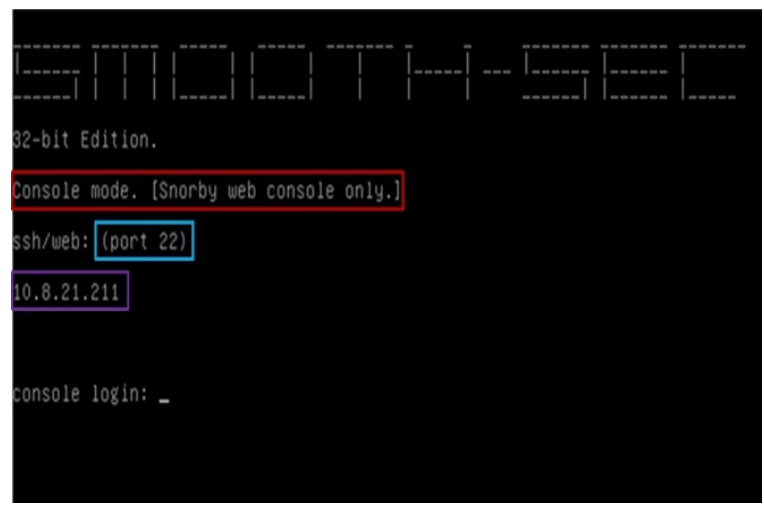

Fig. 11: Smooth-Sec Installed As Console

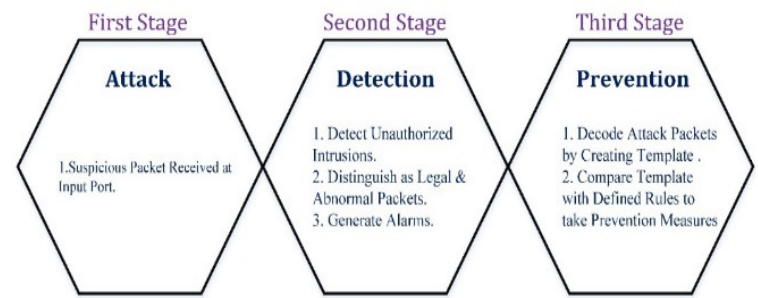

Fig. 12: Stages for Detection and Prevention System

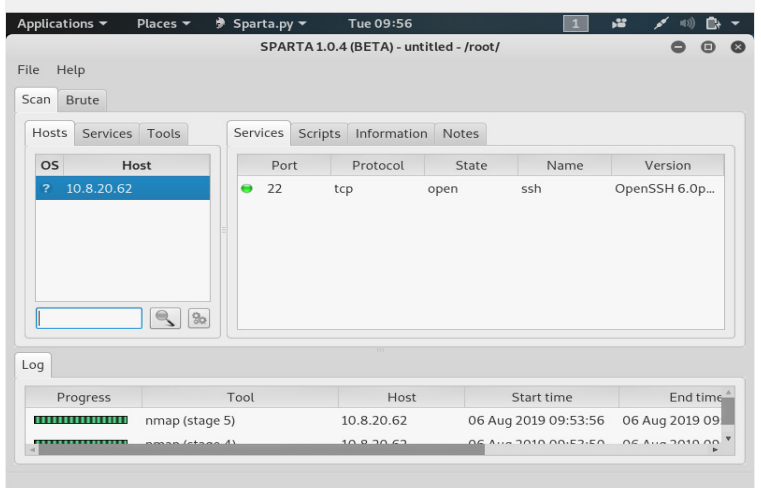

Fig. 13: Kali Linux Operating System for implementing attacks on Hosts

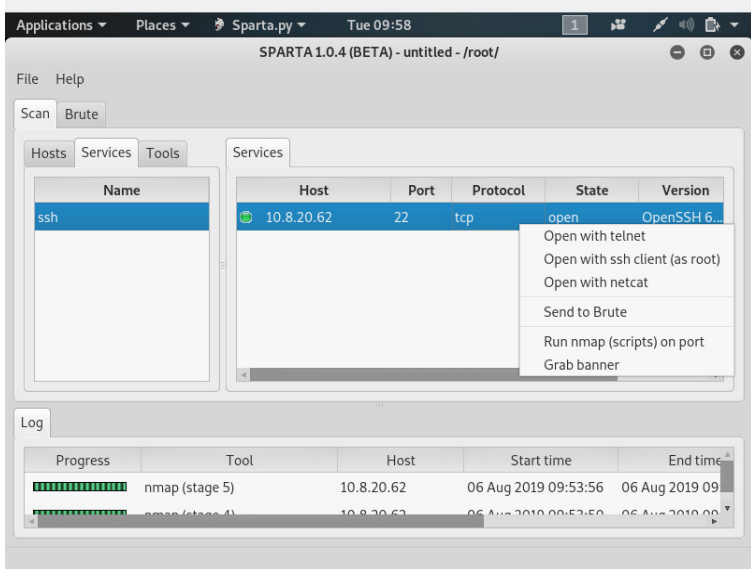

Fig. 14: Types of Implemented Attacks

For this purpose, template of data packet is created. This template contains the IP address and decoded version of the information. Differentiation between normal and abnormal data is carried out by:

1. comparing the IP address of the arrived packet with the IP addresses of the authorized persons. These authorized IP addresses reside in the console library. Whenever, IP address does not match with any of the authorized IP addresses, an alarm triggers and prevention system subsequently blocks the attacker's port as shown in Fig. 16.

2. However, if the attacker copies the IP address of authorized persons residing in the console library, through IP spoofing [14] and impersonates to be the privileged individual; the impersonated IP address matches. In such a case, attacker gains access to the EMS of the $\mu \mathrm{G}$ and tries to enter in the control module through a password. In

Mehran University Research Journal of Engineering and Technology, Vol. 40, No. 4, October 2021 [p-ISSN: 0254-7821, e-ISSN: 2413-7219] 
response to this, the smooth-sec installed as sensor in the EMS informs the system administrator that an unauthorized person is trying to enter into the EMS by impersonating as authorized person. Under such situation, the attacker will be blocked by the sensor as shown in Fig. 17.

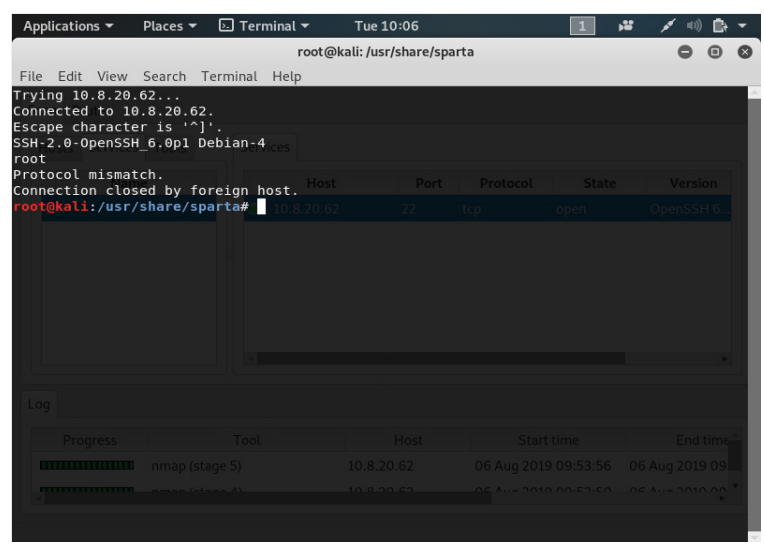

Fig. 15: Open with Telnet Attack (Protocol Mismatch)

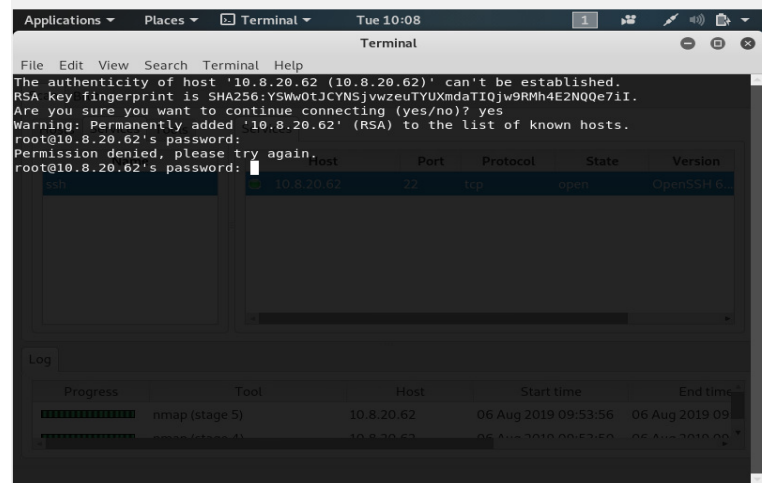

Fig. 16: Open with SSH Client (as Root) Attack (Permission Denied)

\section{CONCLUSION}

This paper proposes a two cored EMS for large scale $\mathrm{I} \mu \mathrm{G}$. Energy core aims to optimally track total energy cost and emission, whereas security core secures the EMS from an internal intruder having access to the local area network to the $\mu \mathrm{G}$. A realistic $\mathrm{I} \mu \mathrm{G}$ containing ICEs, MTs, FCs, BESS and EV lot was modelled. Electric grid, NG and solar PV are considered as input energy carriers. Building takes part in ancillary service market by selling the SR to the national grid. Results show that presence of onsite DERs, BESS, EV lot and SR reduces the energy cost as well as emission, thereby resulting in bilateral benefits of customer and environment. Moreover, simulations encourage the building owners to invest on DERs and batteries to actively and effectively participate in an energy distribution system. Security of EMS has been extremely vital as invasion of an internal or external intruder negatively affects the optimal performance of the energy management module. In comparison to external intruders, internal ones may be more destructive. Therefore, the second part of this work proposes an IDS/IPS scheme. Proposed security approach is validated in smooth-sec software. Simulations show that DoS and password attacks are successfully detected and prevented. Outcome of this work provides a justification to practically implement a cyber secure to cored EMS for large scale industrial microgrid.

\section{ACKNOWLEDGEMENT}

The work has been executed under the worthy guidance of Prof Dr Tahir Nadim Malik and Dr Aamir Raza. Proposed control may be manufactured by utility companies for cyber secured consumption management of large-scale manufacturing facilities.

\section{REFERENCES}

1. Ranjith N.K., Vadana P.D.P., Pillai A.S., "Smart home energy management system - A multicore approach". In: Kamal R., Henshaw M., Nair P. (Eds.) International Conference on Advanced Computing Networking and Informatics. Advances In Intelligent Systems and Computing, Vol. 870, Springer, Singapore.

2. Lokeshgupta B., Sivasubramani S., "Multiobjective home energy management with battery energy storage systems," Sustainable Cities and Society, Vol. 47, 2019.

3. Senemar S., Rastegar M., Dabbaghjamanesh M., Hatziargyriou N. D., "Dynamic Structural Sizing of Residential Energy Hubs", IEEE Transactions on Sustainable Energy, Vol. 11, No. 3, pp. 12361246, 2019.

4. Rosales-Asensio E., de Simón-Martín M., BorgeDiez D., Blanes-Peiró J. J., Colmenar-Santos A., "Microgrids with energy storage systems as a means to increase power resilience: An application to office buildings", Energy, Vol. 172, 
pp. 1005-1015, 2019.

5. Mbungu N. T., Bansal R. C., Naidoo R., Miranda V., and Bipath M., "An optimal energy management system for a commercial building with renewable energy generation under real-time electricity prices", Sustainable Cities and Society, Vol. 41, pp. 392-404, 2018.

6. Liang Z., Bian D., Zhang X., Shi D., Diao R., Wang Z., "Optimal energy management for commercial buildings considering comprehensive comfort levels in a retail electricity market", Applied Energy, Vol. 236, pp. 916-926, 2019.

7. Blake S. T., O'Sullivan D. T., "Optimization of distributed energy resources in an industrial microgrid", Procedia CIRP, Vol. 67, pp. 104-109, 2018.

8. Li H., Eseye A. T., Zhang J., Zheng D., "Optimal energy management for industrial microgrids with high-penetration renewables", Protection and Control of Modern Power Systems, Vol. 2, No. 1, 2017.

9. Golmohamadi H., Keypour R., Bak-Jensen B., Pillai J. R., "A multi-agent based optimization of residential and industrial demand response aggregators", International Journal of Electrical Power and Energy Systems, Vol. 107, pp. 472485, 2019.

10. Naderi M., Bahramara S., Khayat Y., Bevrani H., "Optimal planning in a developing industrial microgrid with sensitive loads", Energy Reports, Vol. 3, pp. 124-134, 2017.

11. Mehta R., "A Microgrid Case Study for Ensuring Reliable Power for Commercial and Industrial Sites", Proceedings of the IEEE PES GTD Grand International Conference and Exposition Asia (GTD Asia), pp. 594-598, Bangkok, Thailand, 2123 March 2019.

12. Choobineh M., Mohagheghi S., "Robust Optimal Energy Pricing and Dispatch for a MultiMicrogrid Industrial Park Operating Based on Just-In-Time Strategy", IEEE Transactions on Industry Applications, Vol. 55, No.4, pp. 33213330, 2019.

13. Khripko D., Dunkelberg H., Summerbell D., Hesselbach J., "Energy Efficiency and demand side management: A case study of a holistic energy concept in polymer processing", Procedia Manufacturing, Vol. 21, pp. 702-709, 2018.
14. Helin K., Käki A., Zakeri B., Lahdelma R., Syri S., "Economic potential of industrial demand side management in pulp and paper industry", Energy, Vol. 141, pp. 1681-1694, 2017.

15. Tan M., Chen Y., Su Y., Duan B., "Simulation planning of power supply capacity: an approach to optimal industrial microgrid operation with carbon emission permits", International Journal of Sustainable Engineering, Vol. 12, No. 5, pp. 19, 2018.

16. Abdulaal A., Moghaddass R., Asfour S., "Twostage discrete-continuous multi-objective load optimization: An industrial consumer utility approach to demand response", Applied Energy, Vol. 206, pp. 206-221, 2017.

17. Anuebunwa U. R., Rajamani H.-S., AbdAlhameed R., Pillai P., "Investigating the Impacts of Cyber-Attacks on Pricing Data of Home Energy Management Systems in Demand Response Programs", Proceedings of the IEEE Power and Energy Society General Meeting (PESGM), pp. 1-5, Portland, O.S., U.S.A., 2018.

18. Yilmaz E. N., Gönen S., "Attack detection/prevention system against cyber attack in industrial control systems", Computers and Security, Vol. 77, pp. 94-105, 2018.

19. Otuoze A. O., Mustafa M. W., Larik R. M., "Smart grids security challenges: Classification by sources of threats", Journal of Electrical Systems and Information Technology, Vol. 5, No. 3, pp. 468-483, 2018.

20. Raza A., Malik T. N., "Energy management in commercial building microgrids", Journal of Renewable and Sustainable Energy, Vol. 11, No. 1, p. 015502, 2019.

21. Alexandropoulos S.-A. N., Aridas C. K., Kotsiantis S. B., Vrahatis M. N., "Multi-Objective Evolutionary Optimization Algorithms for Machine Learning: A Recent Survey", Approximation and Optimization, Vol. 145, pp. 35-55, Springer, 2019.

22. Maglaras L., Ferrag M. A., Derhab A., Mukherjee M., Janicke H., Rallis S., "Threats, Protection and Attribution of Cyber Attacks on Critical Infrastructures", arXiv preprint arXiv:1901.03899, 2019.

23. Shaji R. S., Dev V. S., Brindha T., "A methodological review on attack and defense 
strategies in cyber warfare", Wireless Networks, Vol. 25, No. 6, pp. 3323-3334, 2019.

24. Adams K., "Detecting and preventing man-in-themiddle attacks on an encrypted connection", Ed: Google Patents, 2019.

25. Singhal M., "Analysis and Categorization of Drive-By Download Malware Using Sandboxing And Yara Ruleset", M.S. Thesis, University of Texas at Arlington, May 2019.

26. Pinkas B., Sander T., "Secure authentication systems and methods", Ed: Google Patents, 2019.

27. Raut S., Nikhare A., Punde Y., Manerao S., Choudhary S., "A Review on Methods for Prevention of SQL Injection Attack", International Journal of Scientific Research in Sxience and Technology, Vol. 6, No.2, 2019.

28. Stellios I., Kotzanikolaou P., Psarakis M., "Advanced Persistent Threats and Zero-Day Exploits in Industrial Internet of Things". In Alcaraz C. (Eds.): Security and Privacy Trends in the Industrial Internet of Things, pp. 47-49, Springer, Cham, 2019.

29. Uma M., Padmavahi G., "A Survey on Various Cyber Attacks and their Classification", International Journal of Network Security, Vol. 15, No. 5, pp. 390-396, 2013.

30. Mubin S., Jahan S., Gavirishyk E., "Monte Carlo Simulation and Modeling of Schedule, Cost and Risks of Dasu Hydropower Project", Mehran University Research Journal of Engineering and Technology, Vol. 38, No. 3, 557-570 July 2019.
31. Döring M., Cramer E.. "On the power of goodness-of-fit tests for the exponential distribution under progressive Type-II censoring", Journal of Statistical Computation and Simulation, Vol. 89, No. 16, pp. 1-38, 2019.

32. Khan N. S., Ghani M. S., " Predicting Collective Synchronous State of Sentiments for Users in Social Media", Mehran University Research Journal of Engineering and Technology, Vol. 38, No. 3, pp. 687-704 July 2019.

33. Akram B.A., Zafar A., Akber A., Wajid B., Chaudhry S., "Change Detection Algorithms for Surveillance in Visual IoT: A Comparative Study Visual Internet of Things", Mehran University Research Journal of Engineering and Technology, Vol. 37, No.1, pp. 77-94, 2018.

34. Asghar M., Iqbal M.J., Mustafa G., A Family of High Continuity Subdivision Schemes Based on Probability Distribution, Mehran University Research Journal of Engineering and Technology, Vol. 38, No. 2, pp. 389-398, 2019.

35. Bajwa I.S., Ramzan B., Ramzan, S.. "Markov Logic Based Inference Engine for CDSS", Mehran University Research Journal of Engineering and Technology, Vol. 36, No.1, pp. 55-66, 2017. 